\title{
Heat Pumps
}

\section{Lu Aye}

Renewable Energy and Energy Efficiency Group, Department of Infrastructure Engineering, Melbourne School of Engineering, University of Melbourne, Melbourne, Victoria, Australia

\begin{abstract}
Heat pumps capture heat energy from low-grade heat sources such as ambient air, ground, and waste heat streams and upgrade to a higher temperature level for useful applications. This entry includes a brief history, fundamentals, classifications, applications and performance parameters of heat pumps. Working principles of the thermoelectric heat pump, the absorption heat pump, the gas compression heat pump and the vapor compression heat pump are explained. Performance parameters of the heat pump systems (coefficient of performance, energy efficiency ratio, primary energy ratio, and ambient energy fraction) are presented. The short-term and long-term greenhouse gas saving potential for the use of heat pumps are discussed.
\end{abstract}

Encyclopedia of Environmental Management DOI: 10.1201/9781003043461

Copyright (C) 2020 by Taylor \& Francis. All rights reserved.

\section{INTRODUCTION}

This entry provides foundation knowledge about heat pumps for both professional and non-professional readers. A brief history of heat pumps, basic terms used in the heat pump industry and research and the fundamentals of heat pumps are presented. Working principles of the thermoelectric heat pump, the absorption heat pump, the gas compression heat pump and the vapor compression heat pump are explained by using schematic diagrams. Performance parameters of the heat pump systems - coefficient of performance (COP), energy efficiency ratio (EER), primary energy ratio (PER), and ambient energy fraction (AEF) - are also discussed.

Major advances have been made in heat pump technologies over the last 35 years. "Heat pump systems offer economical alternatives of recovering heat from different sources for use in various industrial, commercial and residential applications." ${ }^{[1]}$ Heat pumps in their various and diverse forms allow one to harness, in a cost-effective manner, solar energy that has already been stored in the atmosphere and biosphere. To make a fair systematic comparison with other systems that provide the same thermal output, AEF may be used. The concept and the method of estimating the AEF are discussed. The relationships between the AEF, the heating coefficient of performance (HCOP) and PER are also presented. The short-term and long-term potential use of the heat pumps and corresponding greenhouse gas (GHG) emissions are discussed. 


\section{Brief History}

Although most people are familiar with the common household refrigerator, the concept of using such a device to provide heating rather than cooling is less widely understood. The basic operational principle of this machine called the heat pump, however, was laid down in thermodynamic terms by Lord Kelvin, the first professor of natural philosophy at the University of Glasgow, Scotland, in the middle of the $19^{\text {th }}$ century. Whereas the thermodynamic principle of the heat pump was found in 1852, it was not until 1855 that it was realized for producing heat by means of an open-cycle mechanical vapor recompression unit in Ebensee, Austria. ${ }^{[2]}$ Much later, the closed vapor compression process was used for generating useful heat. After World War II, heat pump units for air-conditioning homes and individual rooms became common. Now, heat pump technology is well known as one of the energy conservation technologies.

\section{Fundamentals}

A heat pump is a thermodynamic system whose function is to heat, at the required temperature, with the aid of heat extracted from a source at lower temperature. ${ }^{[3]}$ Heat pumps are devices designed to utilize low-temperature sources of energy that exist in atmospheric air, in lake or river water, and in the earth. These sources are referred to as "ambient energies." Heat pumps can also be operated using waste heat from commercial and industrial processes, thereby upgrading this to the required temperature level for some thermal process operations. ${ }^{[4]}$

The heat pump can be considered as a heat engine in reverse ${ }^{[5]} \mathrm{A}$ heat engine removes heat from a high-temperature source and discharges heat to a low temperature and in doing so can deliver work (see Fig. 1). Heat pumps capture heat energy from low-grade sources and deliver at a higher temperature. They require external work $(W)$ to upgrade the heat absorbed $\left(Q_{\mathrm{L}}\right)$ (see Fig. 2). Note that the heat energy flows from a low-temperature heat source to a higher application temperature. This is the reverse of the natural flow direction of heat from a higher temperature to a lower temperature. For ideal conditions without heat losses, the energy balance of a heat pump provides (Eq. 1):

$$
Q_{\mathrm{H}}=Q_{\mathrm{L}}+W
$$

where $Q_{H}$ is the useful heat delivered, $Q_{L}$ is the heat absorbed and $W$ is the work input. 


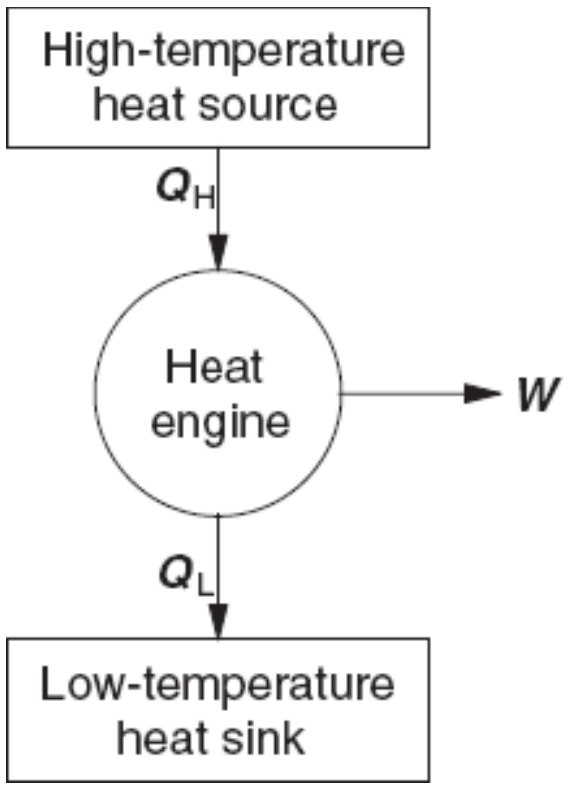

Fig. 1 Thermodynamic model of a heat engine.

The useful heat delivered is always greater than the work input to the heat pump for ideal conditions.

The technical and economic performance of a heat pump is closely related to the characteristics of the heat source. Table 1 lists current commonly used heat sources. Ambient and exhaust air, soil and groundwater are practical heat sources for small heat pump systems, whereas sea/lake/river water, rock (geothermal) and wastewater are generally used for large heat pump systems. ${ }^{[6]}$

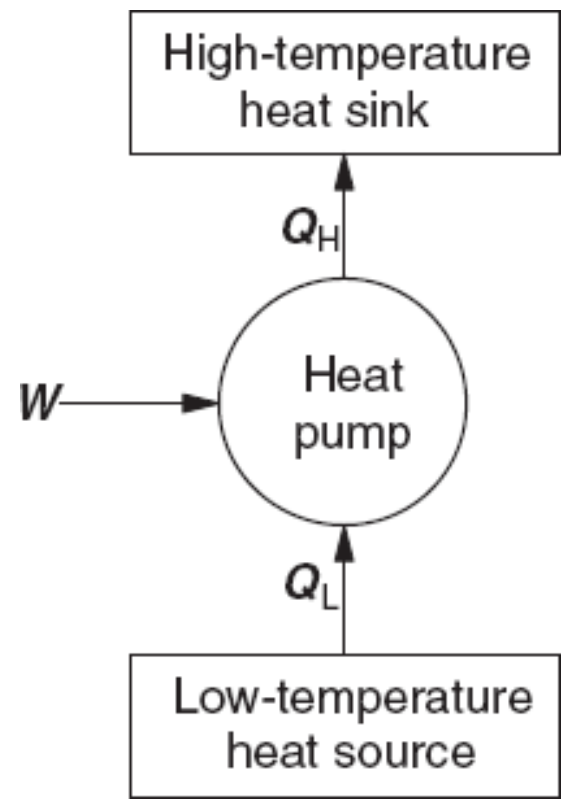

Fig. 2 Energy flow of a heat pump. 
Table 1 Commonly used heat sources.

\begin{tabular}{lc}
\hline Heat source & Temperature range $\left({ }^{\circ} \mathbf{C}\right)$ \\
\hline Ambient air & -10 to 15 \\
Building exhaust air & $15-25$ \\
Groundwater & $4-10$ \\
Lake water & $0-10$ \\
River water & $0-10$ \\
Seawater & $3-8$ \\
Rock & $0-5$ \\
Ground & $0-10$ \\
Wastewater and effluent & $>10$ \\
\hline
\end{tabular}

The fundamental theories of heat pumps and refrigerators are the same. In engineering practice, a distinction is made between heat pumps and refrigerators. The principal purpose of the latter device is to remove heat from a low-temperature heat source, and the purpose of the former device is to supply heat to a high-temperature sink. In many practical devices, the heating and cooling elements are interchangeable. The term reverse cycle air conditioner is frequently applied to heat pumps with interchangeable heating and cooling elements. In Japan and in the United States, reversible air-conditioning units are called heat pumps, and in Europe, the term heat pump is used for heating-only units. ${ }^{[2]}$

\section{CARNOT COEFFICIENT OF PERFORMANCE (THEORETICAL COP)}

The heating performance of a heat pump is measured by the HCOP. The HCOP is the ratio of the quantity of heat transferred to the high-temperature sink to the quantity of energy driving the heat pump (see Fig. 2).

$$
\mathrm{HCOP}=\frac{Q_{\mathrm{H}}}{W}
$$

In the Carnot ideal heat pump cycle, the heat is delivered isothermally at $T_{H}$ and received isothermally at $T_{\mathrm{L}}$. By using the laws of thermodynamics and definition of entropy, it can be shown that the Carnot HCOP is given by Eq. 3 .

$$
\mathrm{HCOP}=\frac{T_{\mathrm{H}}}{T_{\mathrm{H}}-T_{\mathrm{L}}}=\frac{T_{\mathrm{L}}}{T_{\mathrm{H}}-T_{\mathrm{L}}}+1
$$

No practical heat pump constructed can have a better performance than this theoretical ideal HCOP. The best that our practical heat pump cycles can do is struggle towards achieving this ideal performance. $^{[5]}$

\section{FACTS ABOUT HEATING RELEVANT TO HEAT PUMPS}

It is argued that heat pumps are very energy efficient and therefore environmentally benign. The 
International Energy Agency (IEA) Heat Pump Centre provides the basic facts about heat supply and discusses the value of heat pumps. ${ }^{[7]}$ The basic facts about heating explained are as follows:

- Direct combustion to generate heat is never the most efficient use of fuel.

- Heat pumps are more efficient because they use renewable energy in the form of low-temperature heat.

- If the fuel used by conventional boilers were redirected to supply power for electric heat pumps with HCOP of 3.5 to 4.5 , about $35-50 \%$ less fuel would be needed, resulting in $35-50 \%$ less emissions.

- Around 50\% savings are made when electric heat pumps with HCOP of 4.5 are driven by combined heat and power (CHP) or cogeneration systems.

- Whether a fossil fuel, nuclear energy or renewable energy is used to generate electricity, electric heat pumps make far better use of these resources than do resistance heaters.

- The fuel consumption, and consequently the emissions rate of an absorption or gas-engine heat pump is about $35-50 \%$ less than that of a conventional boiler.

Because heat pumps consume less primary energy than conventional heating systems, they are an important technology for reducing the unwanted air pollutants such as respirable particulate matters (PMs), carbon monoxide $(\mathrm{CO})$, nitrogen oxides $\left(\mathrm{NO}_{x}\right)$, sulfur dioxide $\left(\mathrm{SO}_{2}\right)$, and carbon dioxide $\left(\mathrm{CO}_{2}\right)$ that harm the human environment.

\section{Heat Pump Types}

Five major types of heat pump may be identified in the literature. ${ }^{[8,9]}$ These are the following:

- the magnetic heat pump

- the thermoelectric heat pump

- the absorption heat pump

- the gas compression heat pump

- the vapor compression heat pump

\section{The Magnetic Heat Pump}

The magnetic heat pump requires a solid magnetic material and it is based on the magnetocaloric effect. The magnetocaloric effect is the heating and cooling of a magnetic material in response to the application and removal of a sufficiently high external magnetic field. ${ }^{[10]}$ The principle of the magnetic heat pump is shown in Fig. $3{ }^{[11]}$ With thermal Switch 1 off and thermal Switch 2 on, a magnetic field is applied to the solid magnetic material. The solid magnetic material is heated up above the heat sink temperature and heat will flow to the heat sink. Next, thermal switch 1 is on while thermal switch 2 remains on, and the magnetic field is partially removed; this cooled down the magnetic material to the heat source temperature. Thermal switch 2 is then off while the magnetic field is totally removed, completing the cooling of the magnetic material, and the magnetic material gains the heat from the heat source. Thermal switch 2 is then on and a magnetic 
field is applied to heat the magnetic material. Then, thermal switch 1 is off and the cycle is repeated to transfer heat from the low-temperature heat source to the higher-temperature heat sink.

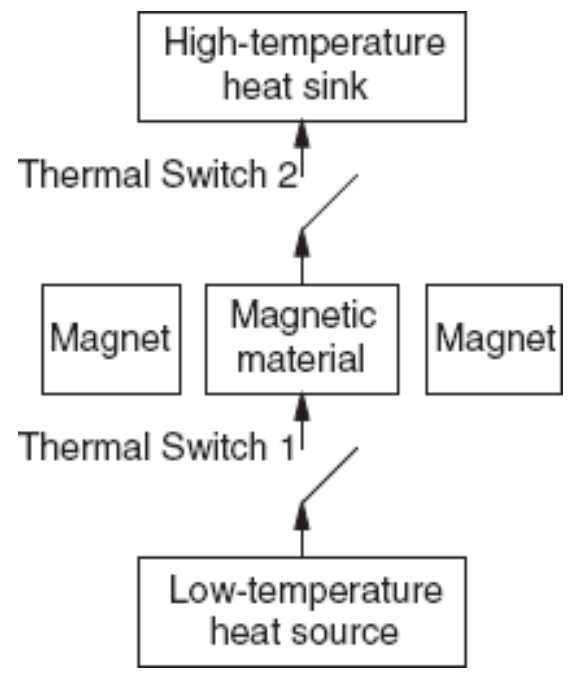

Fig. 3 Schematic of a magnetic heat pump.

The magnetic heat pumps do not use ozone-depleting refrigerants, and they have compact configuration, low noise, high efficiency, high stability, and longevity. They have great applicable prospects. $^{[12,13]}$

\section{The Thermoelectric Heat Pump}

The thermoelectric heat pump uses the Peltier effect. Two materials with different thermoelectric properties ( $p$ type and $n$ type) are arranged to form hot and cold junctions and are connected in series with a direct current voltage source (Fig. 4). These devices do not have moving parts and the cooling and heating elements may be reversed simply by changing the direction of the electric current. Current commercially available thermoelectric heat pumps have efficiencies that are well below those of vapor compression heat pumps. They are generally used in conditions where the solid-state nature (no moving parts, maintenance-free) outweighs efficiency, e.g., cooling of electronic components and small instruments.

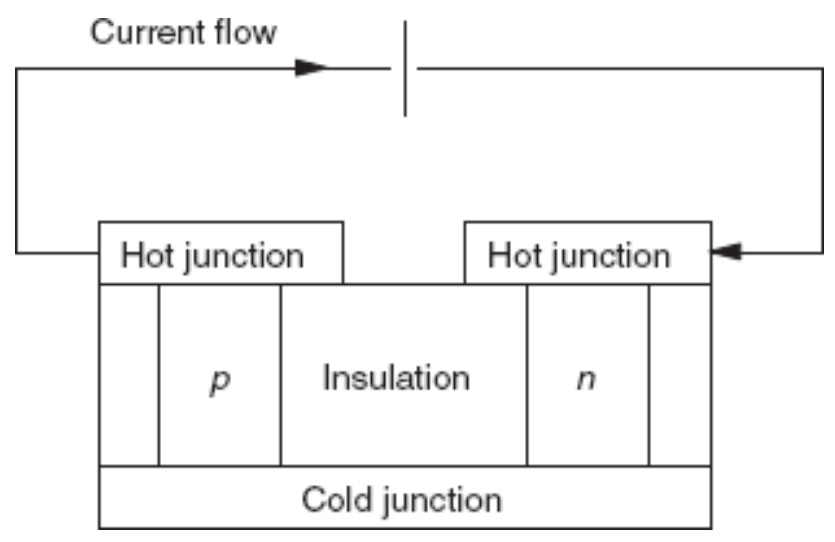


Fig. 4 Schematic of a thermoelectric heat pump.

\section{The Absorption Heat Pump}

An absorption cycle is a heat-activated thermal cycle. The absorption heat pump can be considered as a heat engine driving a heat pump (see Fig. 5). All absorption cycles include at least three thermal exchanges with their surroundings (i.e., energy exchange at three different temperatures). For the system to operate, the generator temperature $\left(T_{\mathrm{g}}\right)$ must be greater than the condenser temperature $\left(T_{\mathrm{c}}\right)$ and the absorber temperature $(T \mathrm{a})$, must in turn be greater than the evaporator temperature $\left(T_{\mathrm{e}}\right)$.

The components of a simple single-effect absorption system are as follows:

- generator (desorber)

- condenser

- refrigerant expansion valve

- evaporator

- absorber

- pump

- solution heat exchanger

- solution pressure reducer

- connecting pipes

The absorption system utilizes a sorbent-refrigerant pair, lithium bromide and water, and water and ammonia, being the most widely used. A schematic of the continuous absorption heat pump system is shown in Fig. 6. The major exchanges with its surroundings are thermal energy, plus a small amount of mechanical work at the pump to transport the working fluids.

A high-temperature heat source supplies heat to the generator to drive off the refrigerant vapor from solution. The condenser receives the refrigerant vapor from the generator. In the condenser, the refrigerant changes phase from vapor to liquid and heat is rejected at a medium temperature. The refrigerant expansion valve reduces the pressure of the refrigerant from the condensing pressure to the evaporating pressure. In the evaporator, the liquid refrigerant collects the low-temperature heat and changes to vapor phase. In other words, the working fluid (refrigerant) provides the cooling effect at the evaporator and the vaporized refrigerant enters the absorber. The strong-concentration sorbent absorbs the refrigerant vapor and becomes a weak solution. Note the heat rejected at the absorber. The low-pressure weak solution (refrigerant and sorbent) is pumped to the solution heat exchanger to exchange heat with the strong-concentration sorbent. The solution pressure reducer accepts the high-pressure strong solution from the generator and delivers low-pressure strong solution to the absorber. The generator receives the high-pressure weak solution from the solution heat exchanger and separates the refrigerant and sorbent. 


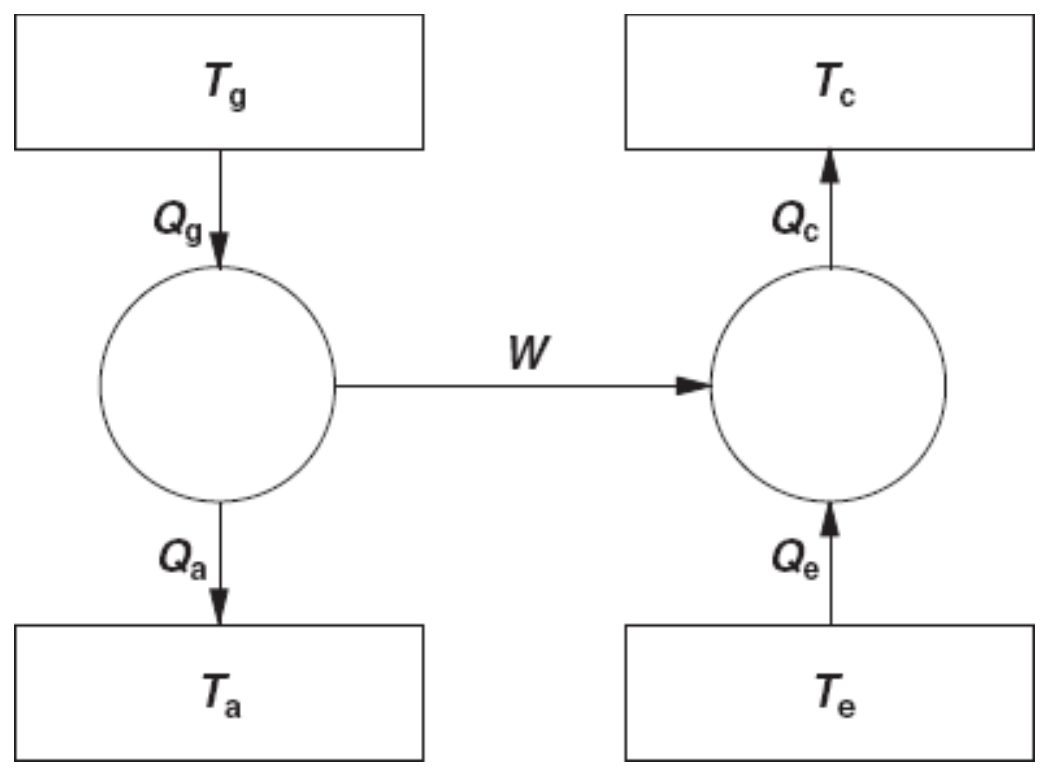

Fig. 5 Thermodynamic model of an absorption heat pump.

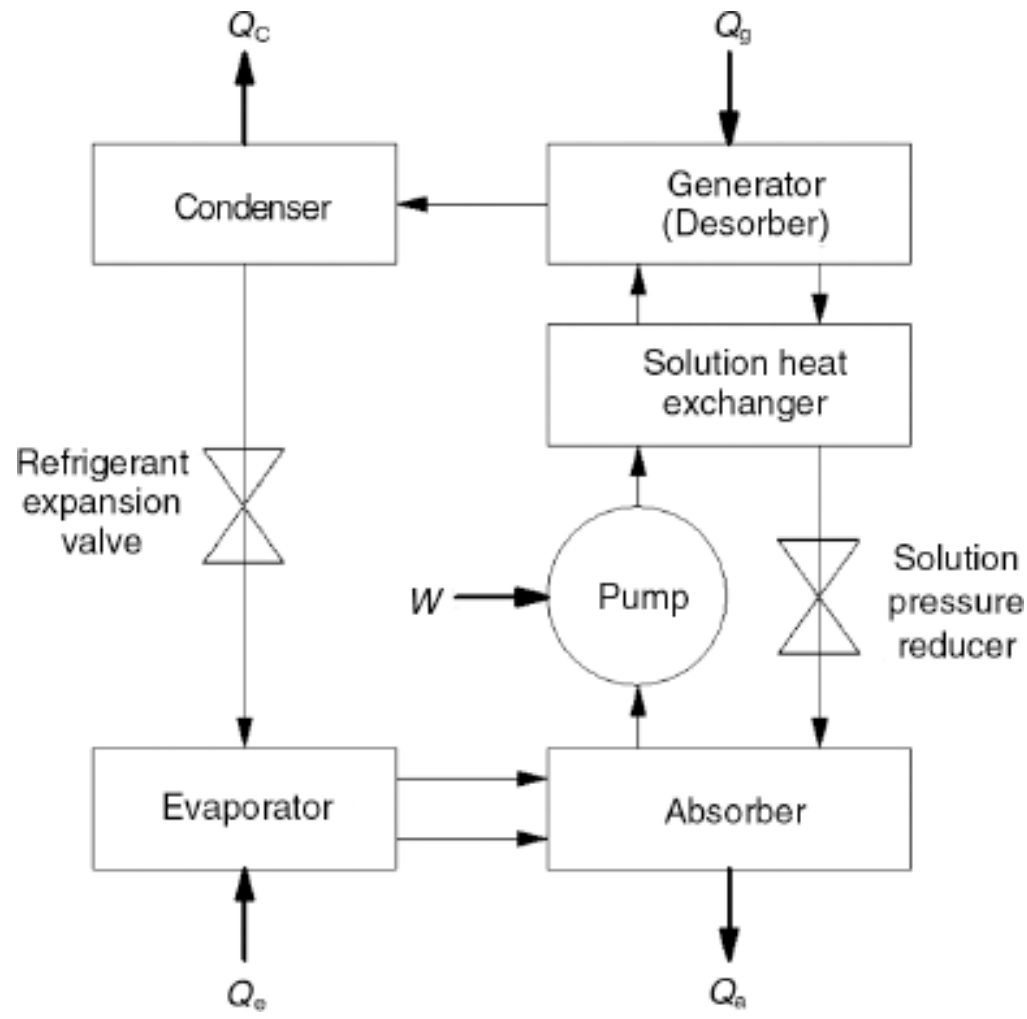

Fig. 6 Simple absorption cycle.

\section{The Gas Compression Heat Pump}

Gas compression heat pumps use a gas as the working fluid. Phase changes do not occur during the cycle of operation. Major components of a gas compression heat pump system are as follows: 
- gas compressor

- high-pressure heat exchanger

- gas expander (or turbine)

- drive motor

- low-pressure heat exchanger

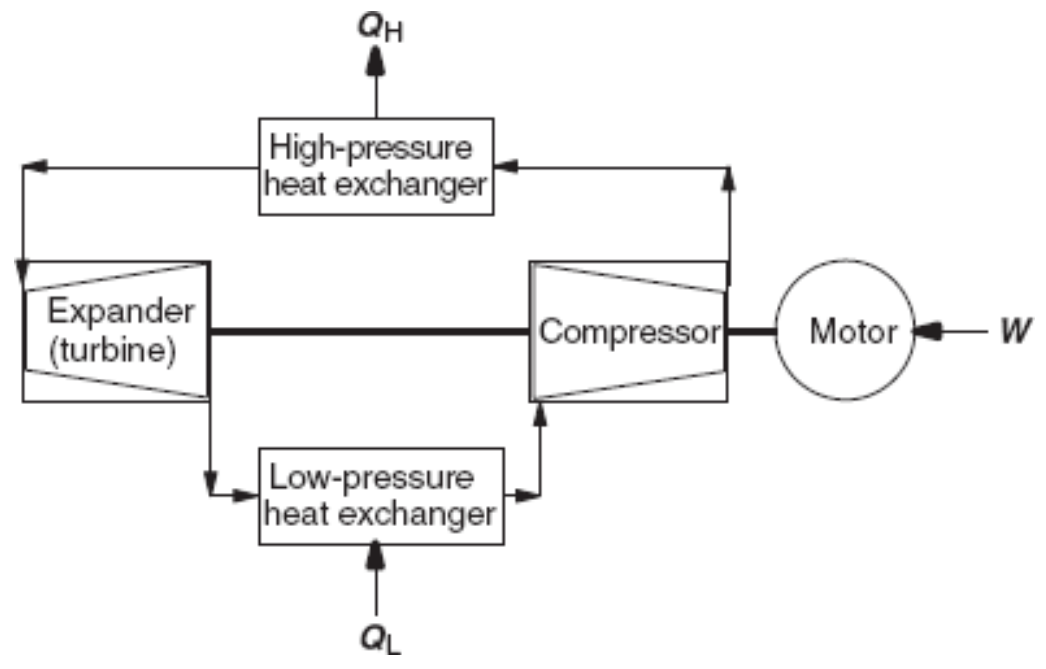

Fig. 7 Schematic of a gas compression heat pump.

A schematic of a gas compression heat pump is shown in Fig. 7. The gas is drawn in to the compressor and compressed. The hot high-pressure gas delivers heat at the high-pressure heat exchanger. At the expander (turbine), the high-pressure gas does expansion work that assists to drive the compressor. In general, the external work input to the compressor-expander system is provided by a drive motor.

\section{The Vapor Compression Heat Pump}

Almost all heat pumps currently in operation are based on either a vapor compression or an absorption cycle. ${ }^{[14]}$ Heat pumps and refrigerators of the vapor compression type utilize a working fluid that undergoes phase changes during operation. The phase changes occur principally during the heat collection and rejection stages of the cycles. The phase-changing processes occurring in the vapor compression heat pumps are accompanied by extremely favorable heat transfer conditions. Boiling agitation in evaporators and dropwise condensation in condensers make the heat transfer rates very high, which helps to improve the system efficiency. To carry out evaporation and condensation, any practical heat pump uses four separate components as illustrated in Fig. 8:

- compressor

- condenser

- expansion device 
- evaporator

The compressor is the heart of the vapor compression heat pump system. By using mechanical power, the compressor increases the pressure of the working fluid vapor received from the evaporator and delivers it to the condenser. The working fluid condenses and provides useful heat at the condenser. The pressure of the liquid working fluid coming out of the condenser is reduced to the evaporating pressure by an expansion device. The low-grade heat is collected at the evaporator and the phase of the working fluid changes from liquid to vapor. The working fluid enters the compressor in vapor form to repeat the cyclic flow. ${ }^{[15]}$

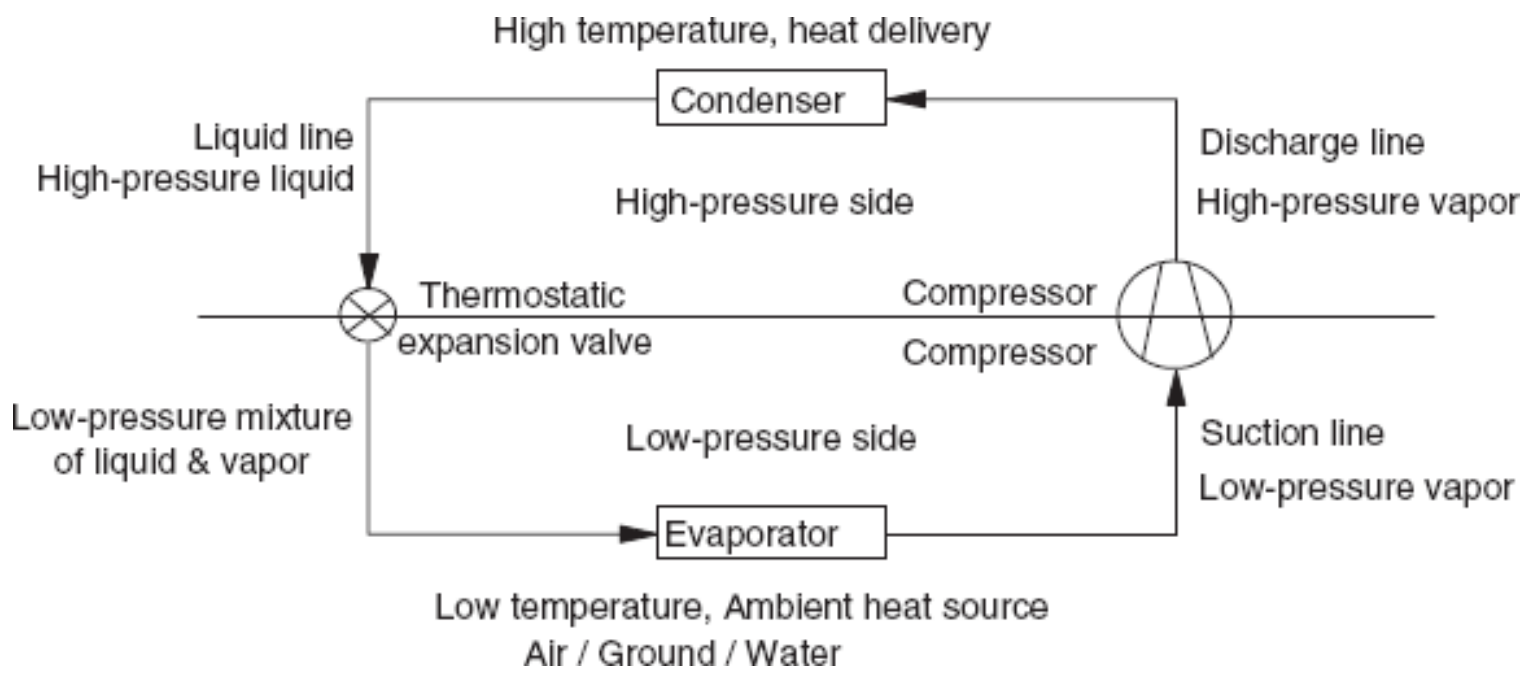

Fig. 8 Schematic diagram of a vapor compression heat pump.

Compressors used in practical units are generally of the positive displacement type: either reciprocating or rotary vanes. In practice, nearly all vapor compression heat pumps use thermostatic expansion ( $\mathrm{T}-\mathrm{X}$ ) valves because of the availability of the valve to handle a wide range of operating conditions and because of the fact that the pressure reduction is essentially isenthalpic. These valves, which are relatively low-cost devices, control the liquid working fluid flow to the evaporator by sensing the superheat condition of the working fluid leaving the evaporator. Such control ensures that nearly all of the available evaporator surface is covered with a forced convection nucleate boiling film with consequential excellent heat transfer characteristics in the evaporation process.

Reversible circuit heat pumps for building cooling and heating are equipped with a four-way exchange valve that can be operated automatically or manually. This valve enables the normal evaporator to become the condenser and the normal condenser to become the evaporator so that the machine can be made to operate in reverse fashion. This arrangement is often incorrectly called reverse-cycle operation because of the end effect achieved-i.e., the interchange of roles for the cooling and heating parts of the circuit. It would be better to call this reverse-flow operation as the basic thermodynamic cycle remains the same for each mode of operation.

In general, vapor compression heat pumps are classified in many different ways. One method 
commonly used distinguishes among air, water and ground sources of low-temperature energy, and also between the high-temperature energy delivery medium (i.e., air or water). In such a classification, the most common types of heat pump units would include air-to-air units and water-to-water units. Solar energy could also be captured at the evaporator as a heat source. These types of heat pumps are called solar-assisted and solar-boosted heat pumps. ${ }^{[16]}$

Changes in condensing and evaporating temperatures affect the work input required at the compressor and consequently the COP. Decreasing the condenser or increasing the evaporator temperatures will decrease the compressor work and increase the COP. Fig. 9 shows the effect of condensing temperature on $\mathrm{COP}$ for a fixed evaporator temperature. The effect of the evaporating temperature on the COP for a fixed condenser load temperature is shown in Fig. 10. For simplicity, these curves have been obtained assuming operation on the ideal heat pump cycle-i.e., the Carnot cycle of two isothermal and two isentropic (reversible adiabatic) processes not allowing any practical deviations. Although the COP values for real machines will be substantially lower, the trend will be the same.

\section{PERFORMANCE PARAMETERS}

This section defines and explains some performance parameters that are used to compare various heat pumps for a particular application and also presents the relationships among them.

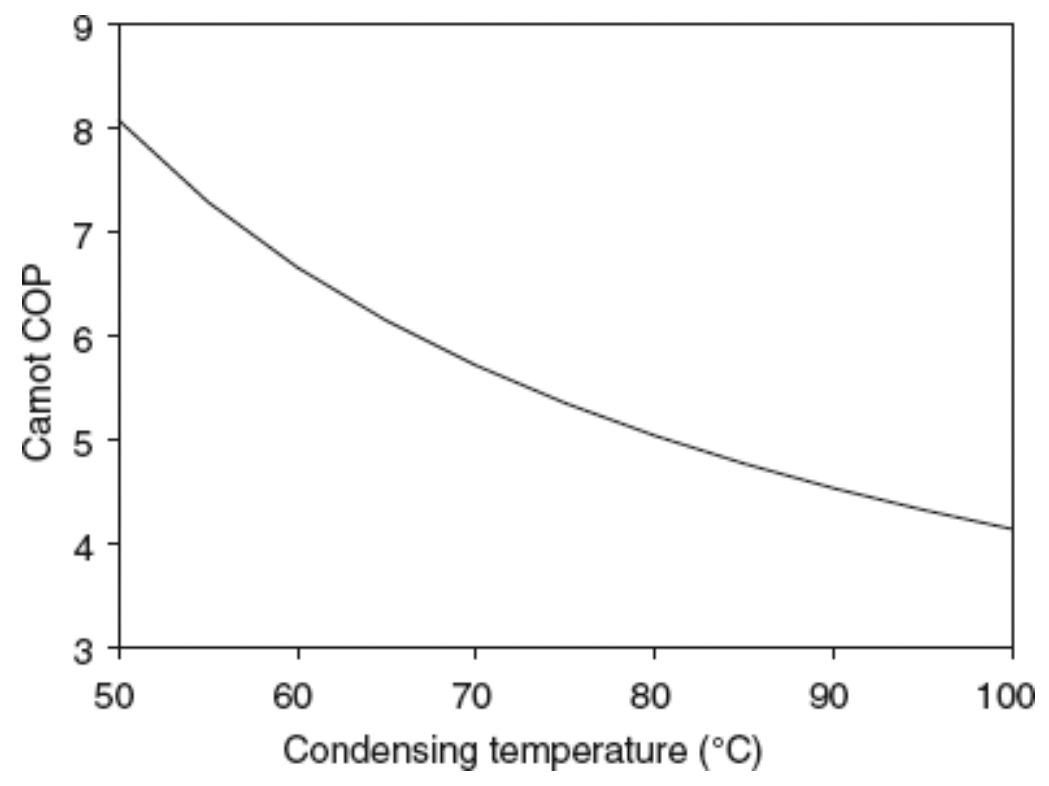

Fig. 9 Effect of condensing temperature on ideal COP (evaporating temperature $=10^{\circ} \mathrm{C}$ ). 


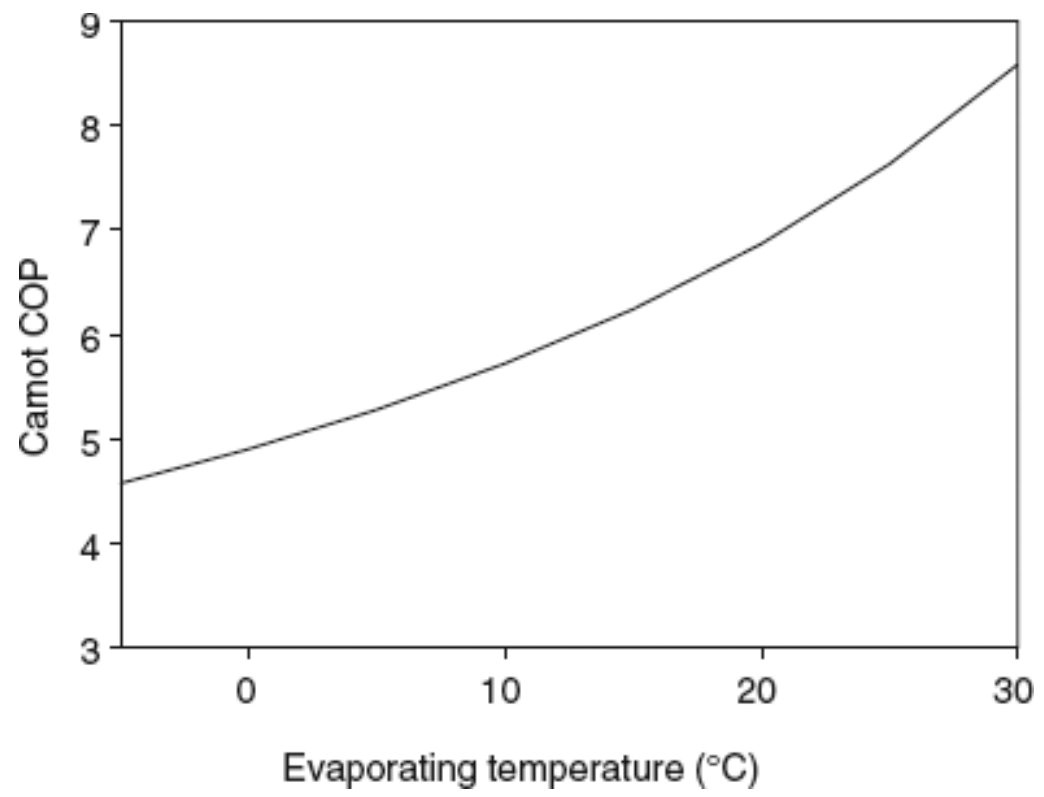

Fig. 10 Effect of evaporating temperature on ideal $\mathrm{COP}$ (condensing temperature $\left.=70^{\circ} \mathrm{C}\right)$.

\section{SCOP and EER}

System coefficient of performance (SCOP) is defined as output heating capacity per unit of power input to the system (see Eq. 4).

$$
\text { SCOP }=\frac{\text { Heating capacity }(\mathrm{W})}{\text { Power input }(\mathrm{W})}
$$

SCOP is a dimensionless number that measures the performance of a heat pump. If the heating capacity is expressed in units other than watts, it is called heating energy efficiency ratio (HEER). Heat pumps sold in the United States are often stated in terms of HEER (see Eq. 5).

$$
\text { HEER }=\frac{\text { Heating capacity }(\mathrm{Btu} / \mathrm{hr})}{\text { Power input }(\mathrm{W})}
$$

Seasonal heating energy efficiency ratio (SHEER) is the time average HEER value for the heating season, and it is also known as seasonal performance factor (SPF). In the equation described, HEER has a unit of "Btu/hr per W." It should be noted that $1 \mathrm{Btu} / \mathrm{hr}=0.2928 \mathrm{~W}$. Therefore, the relationship between HEER and SCOP can be expressed as in Eq. 6.

$$
\text { SCOP }=\text { HEER } \times 0.2928
$$

\section{Primary Energy Ratio}

The HCOP provides a measure of the usefulness of the heat pump system in producing heat from work. It does not express the fact that energy available as work is normally more useful than energy available as heat. To assess different heat pump systems using compressor drives from different fuel or energy sources, the PER is applied. The PER takes into account not only the heat 
pump COP but also the efficiency of conversion of the primary fuel into the work that drives the compressor. PER is defined as in Eq. $7 .^{[5]}$ This can be also expressed as in Eq. 8.

$$
\begin{gathered}
\text { PER }=\frac{\text { Useful heat delivered by heat pump }}{\text { Primary energy consumed }} \\
\text { PER }=\frac{Q_{\mathrm{H}}}{E_{\mathrm{pe}}}=\frac{Q_{\mathrm{H}}}{W} \cdot \frac{W}{E_{\mathrm{pe}}}=\mathrm{HCOP} \cdot \eta_{\mathrm{pp}}
\end{gathered}
$$

where $Q_{\mathrm{H}}$ is the load, $E_{\mathrm{pe}}$ is the primary energy used by the heat pump system, and $\eta_{\mathrm{pp}}$ is the power plant efficiency.

The drive energy of heat pumps is most commonly electricity. "Ideally a heat pump where free work is available should be contemplated e.g., wind or water power." ${ }^{\text {"[ }]}$ Consider an electric heat pump powered by a conventional power plant fueled by a non-renewable energy (see Fig. 11). The power plant efficiency, $\eta_{\mathrm{pp}}$, is up to $58 \%$ for oil- or gas-fired combined-cycle power plants currently available on the market. The PER is equal to the HCOP for direct power generation from renewable ambient energy sources such as solar and wind. ${ }^{[2]}$ This concept is illustrated in Fig. 12.

The amount of renewable or ambient energy spent (used up) to produce work for the heat pump is equal to the amount of work (i.e., $E_{r e}=W$ ). For this case, by definition, $\eta_{\mathrm{pp}}=1 .{ }^{[2]}$ It should be noted that unlike the losses in a fossil fuel power plant, the unused ambient energy passing through the renewable power plant is still in the form of ambient energy and it is available to be used.

\section{Ambient Energy Fraction}

To make a fair systematic comparison of heat pumps and other systems that provide the same heat output, the term $A E F$ was developed by Aye et al. ${ }^{[17]}$ The term solar fraction is widely understood, accepted and used in the solar energy field. It is defined as the fractional reduction of purchased energy when a solar energy system is used. ${ }^{[18]}$ It is the fraction of the load contributed by the solar energy, which can be calculated by Eq. 9 .

$$
f=\frac{L-E}{L}=\frac{L_{\mathrm{s}}}{L}
$$

where $L$ is the load, $E$ is the auxiliary energy supplied to the solar energy system, and $L_{\mathrm{s}}$ is the solar energy delivered. 


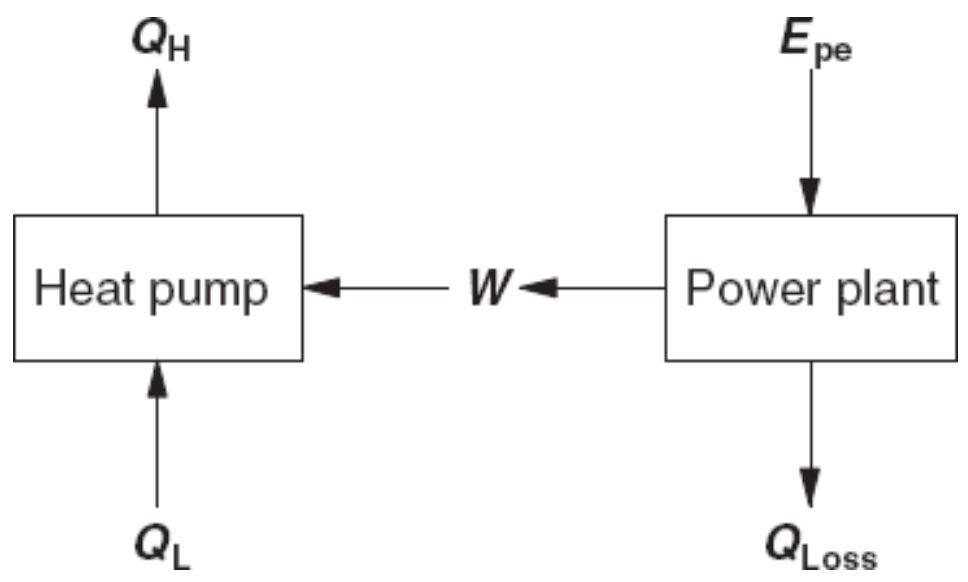

Fig. 11 Energy flow of a conventional electric heat pump.

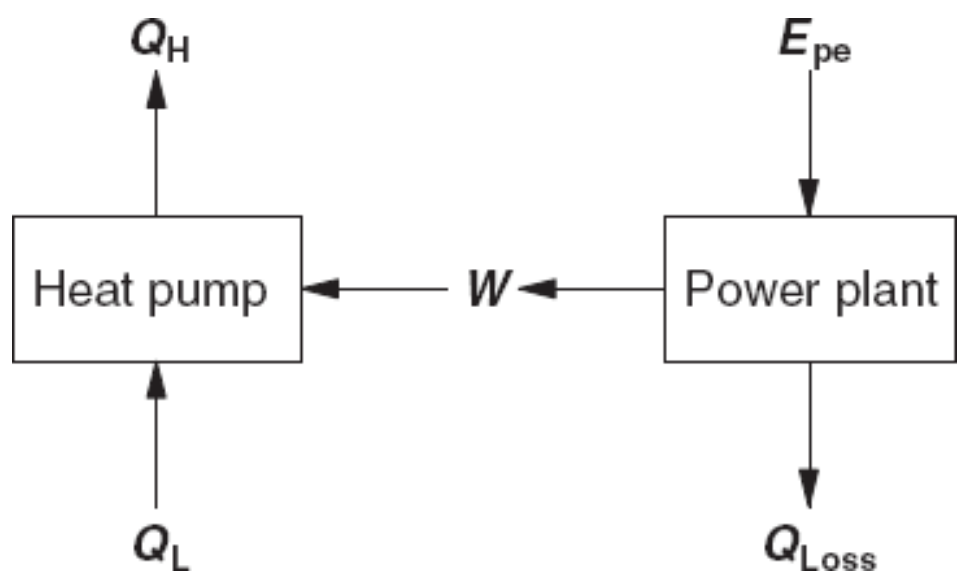

Fig. 12 Energy flow of a renewable electric heat pump.

Similar to the solar fraction of a solar system, the term AEF of a heat pump can be defined as the fraction of the load contributed by the ambient energy, which may be calculated as in Eq. 10 .

$$
\begin{aligned}
\mathrm{AEF} & =\frac{Q_{\mathrm{H}}-E_{\mathrm{pe}}}{Q_{\mathrm{H}}}=1-\frac{E_{\mathrm{pe}}}{Q_{\mathrm{H}}}=1-\frac{1}{\mathrm{PER}} \\
& =1-\frac{1}{\mathrm{HCOP} \times \eta_{\mathrm{pp}}}
\end{aligned}
$$

Fig. 13 illustrates the relationship between the AEF and the PER.

Table 2 shows the AEFs of a heat pump, which has a HCOP of 3.5, for various electric power plants. It can be clearly seen from Table 2 that for the same heat pump, the AEF may vary from 1\% to $71 \%$ depending on how electricity is generated for driving the heat pump compressor. The AEF for the renewable electricity-driven heat pump is the highest (71\%). The renewable energy used is only $29 \%$ (i.e., $100 \%-71 \%$ ) of the total thermal load. The energy use of the brown coal electricity-driven heat pump is $99 \%$ of the total thermal load (i.e., $0.99 \mathrm{MJ}$ of brown coal energy is 
required for $1 \mathrm{MJ}$ of thermal load). Table 3 shows the effect of heat pump COP on the AEF of a heat pump powered by a renewable source.

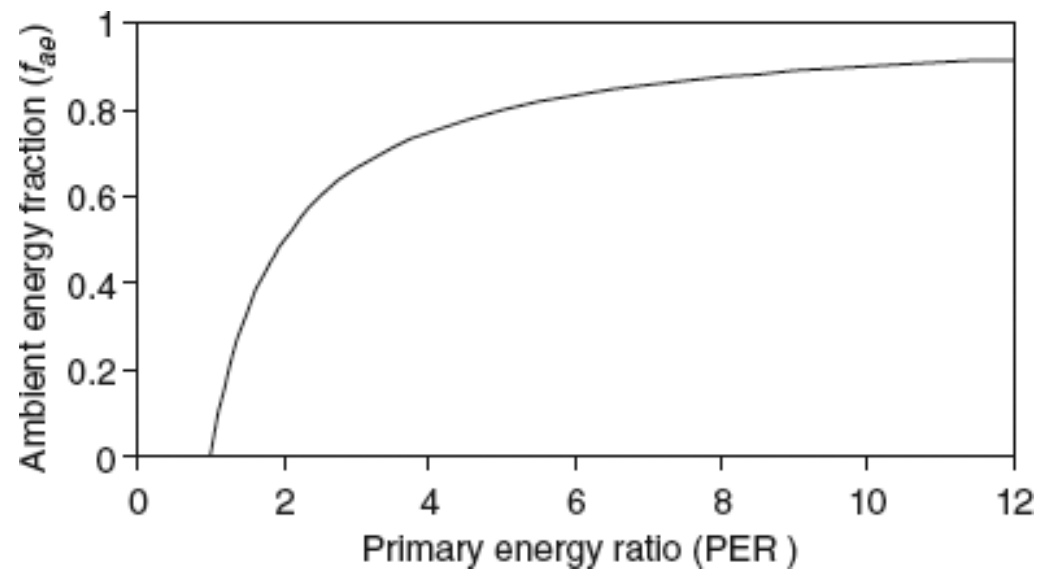

Fig. 13 The AEF versus the PER.

Table 2 AEFs of a heat pump powered by typical power plants.

\begin{tabular}{lccccc}
\hline Power plant & Brown coal & Nuclear & Black coal & $\begin{array}{l}\text { Gas-fired } \\
\text { combined cycle }\end{array}$ & Renewable \\
\hline Power plant efficiency, $\eta_{p p}$ & $0.29^{\mathrm{a}}$ & $0.33^{\mathrm{b}}$ & $0.35^{\mathrm{a}}$ & $0.58^{\mathrm{b}}$ & 1.00 \\
HCOP of heat pump & 3.50 & 3.50 & 3.50 & 3.50 & 3.50 \\
PER & 1.02 & 1.16 & 1.23 & 2.03 & 3.50 \\
AEF & 0.01 & 0.13 & 0.18 & 0.51 & 0.71 \\
\hline
\end{tabular}

Typical Australian data.

Source: Taylor and Labson. ${ }^{[19]}$

${ }^{\text {b}}$ Typical European data.

Source: Gac et al. ${ }^{[3]}$

\section{HEAT PUMP APPLICATIONS}

Heat pumps have been used for domestic, commercial, and industrial applications.

Domestic applications are as follows:

- provision of space heating

- provision of hot water

- swimming pool heating

Commercial and industrial applications are as follows:

- space heating

- water heating

- swimming pool heating

- drying and dehumidification 
- evaporation and boiling

- desalination

\section{POTENTIAL FOR THE USE OF HEAT PUMPS}

In 2000, the primary energy used in buildings was $149 \mathrm{EJ}$, and the world total primary energy used was 387 EJ. ${ }^{[20]}$ The building sector represented $38 \%$ of the total primary energy use and $34 \%$ of the total GHG emissions in 2000. Price et al. ${ }^{[20]}$ reported that, in 2004, the emissions from the building sector, including the electricity consumed, were $8.6 \mathrm{Gt} \mathrm{CO}_{2}, 0.1 \mathrm{Gt} \mathrm{CO}_{2-\mathrm{e}} \mathrm{N}_{2} \mathrm{O}, 0.4 \mathrm{Gt} \mathrm{CO}_{2-\mathrm{e}} \mathrm{CH}_{4}$,

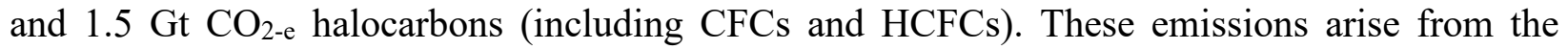
following:

- direct combustion of fossil fuels in residential and commercial buildings, amounting to 3.3 $\mathrm{GtCO}_{2}$ (almost $1.7 \mathrm{GtCO}_{2}$ from combustion of oil, around $1.3 \mathrm{GtCO}_{2}$ from gas, and about 0.3 $\mathrm{GtCO}_{2}$ from coal ${ }^{[21]}$

- indirect or upstream $\mathrm{CO}_{2}$ emissions from the demand of electricity and district heat were about $5.4 \mathrm{GtCO}_{2}{ }^{[21]}$

- combustion of biomass produces $\mathrm{N}_{2} \mathrm{O}$ and $\mathrm{CH}_{4}$ equivalent to $0.5 \mathrm{GtCO}_{2-\mathrm{e}}$

- refrigerant or working fluid (halocarbons) leakages accounting for $1.5 \mathrm{GtCO}_{2-\mathrm{e}}$

In 2004 , about $60 \%$ of total GHG emissions generated by the building sector $\left(6.5 \mathrm{GtCO}_{2 \text {-e }}\right.$ out of $\left.10.7 \mathrm{GtCO}_{2-\mathrm{e}}\right)$ is estimated to be due to space heating, space cooling, and water heating. Heat pumps can meet these requirements in all types of buildings. Many low-temperature industrial heating requirements can also be met by heat pump technology. It is apparent that heat pumps have a large potential for saving energy and GHG emissions due to buildings. Energy and GHG saving potential of heat pumps can be estimated by using PER, one of the heat pump performance parameters presented. Table 4 shows the estimated GHG saving potential. The following assumptions were made for these estimations until 2030:

- annual GHG emissions growth rate for the building sector is $2.5 \%$

- annual market growth rate for vapor compression heat pump is $10 \%$

- HCOP improvement is $1 \%$ per annum

- annual global average power plant efficiency improvement is 3\%

Table 3 Effect of HCOP on AEF of a heat pump powered by a renewable source.

\begin{tabular}{lcccc}
\hline HCOP of heat pump & 1.50 & 2.50 & 3.50 & 4.50 \\
Renewable power plant & 1.00 & 1.00 & 1.00 & 1.00 \\
efficiency, $\eta_{\text {pp }}$ & & & & \\
PER & 1.50 & 2.50 & 3.50 & 4.50 \\
AEF & 0.33 & 0.60 & 0.71 & 0.78 \\
\hline
\end{tabular}


Table 4 GHG saving potential of heat pumps (space heating, space cooling, and water heating applications) for the building sector.

\begin{tabular}{lllll}
\hline & $\mathbf{2 0 0 4}$ & $\mathbf{2 0 1 0}$ & $\mathbf{2 0 2 0}$ & $\mathbf{2 0 3 0}$ \\
\hline GHG emissions from buildings $\left(\mathrm{GtCO}_{2-\mathrm{e}}\right)$ & 6.5 & 7.5 & 9.6 & 12.4 \\
Heat pump market share $(\%)$ & 3 & 5 & 14 & 36 \\
HCOP & 3.5 & 3.7 & 4.1 & 4.5 \\
Average power plant efficiency $(\%)$ & 30 & 36 & 48 & 65 \\
Global average PER & 1.05 & 1.33 & 1.98 & 2.93 \\
GHG saving $\left(\mathrm{Mt} \mathrm{CO}_{2-\mathrm{e}}\right)$ & 9 & 100 & 657 & 2911 \\
\hline
\end{tabular}

The GHG reduction potential of about $3 \mathrm{GtCO}_{2-\mathrm{e}}$ in 2030 was estimated for the building sector alone. The IEA Heat Pump Centre reported a minimum of $0.2 \mathrm{GtCO}_{2 \text {-e }}$ saving potential by industrial heat pumps in 1997, an estimation based on a study by project Annex 21. The total GHG reduction potential of $1.2 \mathrm{GtCO}_{2 \text {-e }}$ was estimated in the year 2010 by IEA HPC. "This is one of the largest that a single technology can offer and this technology is already available in the market place."[22]

\section{CONCLUSIONS}

The fundamentals of heat pumps have been presented together with the working principles of the thermoelectric heat pump, the absorption heat pump, the gas compression heat pump and the vapor compression heat pump. It should be noted that vapor compression heat pumps driven by electricity dominate the current market. Heat pumps are very energy-efficient and therefore environmentally benign compared to other available heating technologies. The technical and economic performance of a heat pump is closely related to the characteristics of the heat source.

Various performance parameters are available for comparing heat pumps; HCOP and HEER are the most widely used. PER and AEF can be used to compare various heat pump systems systematically and fairly. The AEF of an electric heat pump depends on the HCOP and the power plant efficiency based on the primary energy used. The AEF is highly dependent on the type of power plant used to generate the electricity that drives the heat pump compressor. Heat pumps driven by renewable electricity offer the possibility of reducing energy consumption significantly. In the future, the AEF may be used widely as a performance parameter of heat pumps since energy resource issues are becoming more important.

\section{ACKNOWLEDGMENTS}

I wish to thank Emeritus Professor William W. S. Charters, former Dean of Engineering at the University of Melbourne, who introduced me to heat pump technology and for supporting my career and research in heat pumps. 


\section{REFERENCES}

1. Chua, K.J.; Chou, S.K.; Yang, W.M. Advances in heat pump systems: A review. Appl. Energy 2010, 87 (12), 3611-3624.

2. Halozan, H.; Rieberer, R. Energy-efficient heating and cooling systems for buildings. IIR Bulletin, 2004, LXXXI (2004-6), 6-22.

3. Gac, A.; Vrinat, G.; Blaise, J.-C.; Camous, J.-P.; Fleury, M. Guide for the Design and Operation of Average and Large Capacity Electric Heat Pumps; International Institute of Refrigeration: Paris, 1988.

4. McMullen, J.T.; Morgan, R. Heat Pumps; Adam Hilger Ltd: Bristol, U.K., 1981.

5. Reay, D.A.; Macmichael, D.B.A. Heat Pumps Design and Applications: A Practical Handbook for Plant Managers, Engineers, Architects and Designers; Pergamon Press: Oxford, 1979.

6. IEAHPC (International Energy Agency Heat Pump Centre). Heat Sources. Available at http://www.heatpumpcentre.org/About_heat_pumps/Heat_sources.asp (accessed September 2005).

7. IEAHPC (International Energy Agency Heat Pump Centre). How Heat Pumps Achieve Energy Savings and $\mathrm{CO}_{2}$ Emissions Reduction-An Introduction. Available at http://www.heatpumpcentre.org/About_heat_pumps/Energy_and_CO $\mathrm{CO}_{2}$.asp (accessed September 2005).

8. Brown, G.V. Magnetic heat pumping near room temperature. J. Appl. Phys. 1976, 47 (7), 3673-3680.

9. Taylor, L.E. The Design, Construction, and Evaluation of a Solar Boosted Heat Pump; Master of Engineering Science thesis, Department of Mechanical Engineering, The University of Melbourne, 1978.

10. Phan, M-H.; Yu, S.-C. Review of the magnetocaloric effect in manganite materials. J. Magn. Magn. Mater. 2007, 308 (2), 325-340.

11. Steyert, W.A. Stirling-cycle rotating magnetic refrigerators and heat engines for use near room temperature. J. Appl. Phys. 1978, 49 (3), 1216-1226.

12. Yu, B.; Liu, M.; Egolf, P.W.; Kitanovski, A. A review of magnetic refrigerator and heat pump prototypes built before the year 2010. Int. J. Refrig. 2010, 33 (6), 1029-1060.

13. Yu, B.F; Gao, Q.; Zhang, B.; Meng, X.Z.; Chen, Z. Review on research of room temperature magnetic refrigeration. Int. J. Refrig. 2003, 26 (6), 622-636.

14. IEAHPC (International Energy Agency Heat Pump Centre). Heat Pump Technology. Available at http://www.heatpumpcentre.org/Aboutheatpumps/HP_technology.asp (accessed September 2005).

15. Aye, L.; Charters, W.W.S. Electrical and engine driven heat pumps for effective utilisation of renewable energy resources. Appl. Therm. Eng. 2003, 23 (10), 1295-1300.

16. Aye, L.; Charters, W.W.S; Chaichana, C. Solar boosted heat pump. Progress in Solar Energy Research; Nova Science Publishers, Inc.: NY, 2006.

17. Aye, L.; Fuller, R.J.; Charters, W.W.S. Ambient energy fraction of a heat pump. In Solar 2005, Renewable Energy for a Sustainable Future-A challenge for a post carbon world, Proceedings of the 43rd Annual Conference of Australian and New Zealand Solar Energy Society, November 28-30, 2005, Dunedin, 2006.

18. Duffie, J.A.; Beckman W.A. Solar Engineering of Thermal Processes, 2nd Ed.; A Wiley-Interscience Publication: New York, 1991.

19. Taylor, M.; Labson, S. Profiting from Cogeneration. DPIE: Commonwealth Department of Primary Industries and Energy/Australian Cogeneration Association: Canberra, Australia, 1997. 
20. Price, L.; de la Rue du Can, S.; Sinton, J.; Worrell, E.; Nan, Z.; Sathaye, J.; Levine, M. Sectoral Trends in Global Energy Use and Greenhouse Gas Emissions; Lawrence Berkeley National Laboratory: Berkeley, CA. LBNL-56144, 2006.

21. Stern, N.H. The Economics of Climate Change: The Stern Review; Cambridge University Press: Cambridge, 2007.

22. IEAHPC (International Energy Agency Heat Pump Centre). How Heat Pumps Achieve Energy Savings and $\mathrm{CO}_{2}$ Emissions Reduction: An Introduction, 2010. Available at http://www.heatpumpcentre.org/en/aboutheatpumps/howheatpumpsachieveenergysavings/Sidor/defa ult.aspx (accessed August 2010). 


\section{University Library}

\section{- M M I N E R VA A gateway to Melbourne's research publications}

Minerva Access is the Institutional Repository of The University of Melbourne

Author/s:

Aye, L

Title:

Chapter 37: Heat Pumps

Date:

2020-07-29

Citation:

Aye, L. (2020). Chapter 37: Heat Pumps. Fath, BD (Ed.). Jørgensen, SE (Ed.). Cole, M (Ed.). Managing Air Quality and Energy Systems, (Second), pp.617-631. CRC Press.

Persistent Link:

http://hdl.handle.net/11343/258495 